\title{
The Role of Production Planning in Enhancing an Efficient Manufacturing System - An Overview
}

\author{
Sunday A. Afolalu ${ }^{1}$, Omolayo M. Ikumapayi ${ }^{2 *}$, Samuel A. Ushe ${ }^{1}$, Samuel O. Ongbali ${ }^{1}$, Ademola Abdulkareem ${ }^{3}$, Moses E. \\ Emetere $^{4}$, Olamma U. Iheanetu ${ }^{5}$ \\ ${ }^{1}$ Department of Mechanical Engineering, Covenant University, Ota, 112233, Nigeria. \\ ${ }^{2}$ Department of Mechanical and Mechatronics Engineering, Afe Babalola University, Ado Ekiti, 360101, Nigeria \\ ${ }^{3}$ Department of Electrical and Electronic Engineering, Covenant University, 112233, Nigeria. \\ ${ }^{4}$ Department of Physics, Covenant University, Ota, 112233, Nigeria \\ ${ }^{5}$ Department of Computer Science, Covenant University, Ota, 112233, Nigeria
}

\begin{abstract}
Every manufacturing system can only survive with a high level of system planning and budgeting. Production planning is a sequential ladder in the manufacturing setting to ensure that materials input (raw materials, men, money, and machine) is made available within a stipulated time frame, in the appropriate amount to produce the demanded output of goods and services based on the schedule specified. Production planning also helps in making available high quality of goods and services in the right quantities to the customer at the demanded delivery timing to attain higher degree of customer satisfaction. Through production planning, different departmental activities i.e., engineering, production, purchasing, sales, and marketing, as well as stock control department, and other units that may relate to production are coordinated to attain a regular, steady, and balanced flow of production thus, enhancing reduction in production cycle time. Production planning serves as an instrument which estimates to gear up the performance of different departments and individuals of an organization in such a manner that will enhance better service to customers, fewer rush orders, more efficient use of equipment, reduced idle time of both machine and personnel, improved plant morale, good public image, and lower capital requirement, it may also create alternative plans to meet any form of emergency or contingency during the cause of production. From the foregoing, a manufacturing system that incorporates production planning in its operations will be more efficient, effective, and economical as compared with those that did not.
\end{abstract}

\section{Introduction}

Production Planning (PP) is the center of operation of any productive and profiting firm. It encompassed sorting out the sustaining and satisfying factors of both the firm's management system, managing suppliers, and the customers [1]. A firm with a dynamic business model will tend to unprofitably consume cost in terms of time and monetary value on redundant activities when its production process is based on guess operation rather than operating on a carefully analyzed planned market and customers' demand [2]. Inadequate forecast on the production line during planning may tend to increase cost and jeopardized the production output and profiting of a firm as a corporate entity [3]. The capacity to determine exactly what to produce, how to produce, when to produce, where and how much quantity to be produce at a particular period is what will make a firm to adequately stand out and compete favorably in the production market [4]. This thus makes production planning a vital instrument in the manufacturing system. This, therefore, demands firms, irrespective of their size, to seize the opportunity to embark on strategic planning during production process [5].

Production process demands adequate planning to transform inputs resource such as man power, raw materials, capital, information, energy, among others into a demanded output such as finished products and services in appreciable quality and quantity, hence attaining organizational objectives of as an enterprise [6] which will increase the market value of the goods and the firm. Production planning is a sequential ladder in the production process in a manufacturing setting to ensure that materials (raw materials, men, money, and machine) are made available within a stipulated time frame, in the appropriate amount to produce the demanded output of goods and services based on the schedule specified [7]. Production planning is a managerial activity of an organization that is saddled with the responsibility to decide production facilities requirement considering space availability and the market demands of goods and services to produce [8]. While production is the transformation and creation of goods/services to satisfy human needs, production is thus considered as the act of transforming processing inputs resources into finished goods and services via

*Corresponding author:ikumapayi.omolayo@abuad.edu.ng 
physical resources [9]. It also involves the transformation of raw materials or purchased components or semi-finished products into finished products for sale [10]. Production is generally considered as the conversion process of raw materials into finished products such as goods and services [11]. Manufacturing system is made of large number of components that demands effective management to obtain the right outputs of appropriate quantities, qualities, minimal production cost and at the right desired time frame [12].

Organization operating with multiple products, diverse plants and warehouses, a wider range of equipment and operations, production management requires more complicated level of decisions and planning that affect several organizational echelons [13]. Production planning being a crucial tool in the production management systems is an instrumental factor in enterprise operational management. Production planning offers an exceptional role in local manufacturing industries due to the high cost of production line maintenance, raw materials, and energy consumption [14]. This relies majorly on the execution of effective production management policy and the method of optimizing production plans. This aids improvement of production efficiencies, reduction in production costs, and maximization of profit in the advancing competitive system [15]. Production planning is used in diverse researching fields including production and operation management, operations research, artificial intelligence, cognitive sciences, among others to aid how production can effectively be carried out without break in production line with minimum production cost and maximum profiting [16].

\subsection{Challenges impacting on production planning}

Every operation comes up with its challenges, the major challenging factor this work is aimed at achieving is establishing the effectiveness of organizational productivity through production planning [17]. Lack of insight by organizations to comprehend the demands of customers regarding the assortment of products, their functionality, availability, durability, and features leads to poor performance in the production sector [18]. When there is no match between the desire of customers and what the organization offers, the organization would with time lose its position in the market [19]. Factors such as dynamic changes in market condition, high fluctuation in resources utilization in the production process, high rate of change in customers demand have the capacity to influence the execution of tasks and attainment of the objectives of production planning and control customers desires with respect to the product assortment persuasion, functionality, availability, durability, and features [20]. Production planning is dynamic and it exists ina fluid state since plans may change due to the changes in conditions. The effectiveness of production planning can be enhanced through control. The control process in production is a parameter that measures the level of execution of plans [21]. It ensures production operations commenced at the scheduled points or venue and schedule times, Observed continuity in operation line and taking accurate records, analyzed the documented data with the set plans and evaluation of any deviation or abnormality, making any correction to reduce the abnormal impact in deviations from the plans and giving feedback of the documented information to the planning department for immediate adjustment in the plans [22]. The processes of production in processing industries are not flexible, which makes it difficult for any time change in starting a new line of production product on a technological line. Also, there is always little program assortment whereby many final products are just variations of certain numbers of basic products [23].

\section{Production Planning Models}

There had been immersing research and contribution by researchers and scholars to implement diverse means of optimizing manufacturing challenges through production planning. The fundamental optimization methodology for production planning includes the following models [24]: linear programming, dynamic programming, and fuzzy logic mathematical programming, among others. Mathematical programming is one of the outstanding methodologies to ascertaining production planning effectively [25]. Elongated linear programming model which operates on two-level determining equivalent challenge was proposed by Byrne [2] to evaluate multi-period and product uncertainty production planning model. A novel interactive possibility linear programming technique was used by Afolalu et al. [25] to solve the multi-product aggregating production planning issues through unprecise forecast in relation to operational costs and capacity Mula et al, [26] in his work made a review on some existing works of literature of uncertainty modeling in production planning problems. Kall and Mayer [18] through linear and nonlinear programming methods reviewed and discussed on single-stage stochastic linear programming (SLP) models and multi-stage SLP models. Singhvi et al. (2004) established a graphical representation that depicts the demand and supply information as composite curves and draws insight from pinch analysis. Mulaet al. [26] also discovered a technique of dynamic programming application on the procedure to apply to attain maximal control, Markovian decision problems, planning and sequential decision making under uncertainty, and discrete/combinatorial optimization. There are little research works on the area of fuzzy production planning. Attempt was made by Kinkel et al. [10] to apply a new fuzzy linear programming-based method with a modification in Scurve membership function to resolve the fuzzy mix product selection barrier in engineering industry. More breakthroughs can be achieved by applying fuzzy mathematical programming in production planning 
challenges can be discovered. Kopanos et al [21] was able to show forth a new continuous-time precedencebased MILP scheduling framework for handling sequence-dependent time setup and/or cost constrains in batch plants. Also, Salawu et al. [28] were able to present a scheduling model formulated as a MILP problem used for multi-product batch plant with parallel units based on a heuristic approach. The lack of application of these models is due to the myopic state of scheduling research and this is because concern centered only on a part of a situation [29]. Crawford et al. (1999), stated that there is difficulty in the study of scheduling reason being that it can only be completely studied in an environment where it is always found, that is, a complex, dynamic manufacturing system [11]. The operational framework shows the existence of a relationship between production planning and organizational effectiveness [30]. This is assumed on the ground that production planning can assist any organization and eliminate excessive work-in-process. In addition, production planning enhances the full utilization of human resources, enhanced on-time deliveries in reaching customers demand, increased customer satisfaction, improves sales and ensures that there is optimum equipment utilization [20].

\subsection{Objectives of Production Planning and Control}

i. To make available high quality of goods and services in the right quantities to the customer at the demanded delivery timing to attain a higher degree of customer satisfaction [31, 32],

ii. To attain optimize resources/material utilization $[31,32]$,

iii. To reduce the production/manufacturing cycle time [31, 32],

iv. To ensure that optimum inventory levels are maintained [31, 32],

v. To schedule production system to an optimum degree [31, 32],

vi. To coordinate diverse departmental activities that may relate to production to attain regular, steady, and balanced flow of production [31, 32],

vii. To make sure confirmatory commitments of delivery is maintained $[31,32]$

\subsection{Factors Limiting the Impact of Production Planning and Control}

The below-listed factors tend to limit the impact of PPC based on the review literature:

i. The interdependence of diverse operations involving the transformation process/stages [31]

ii. The nature and quality of products [32].

iii. The forms and availability of different equipment and materials used in the manufacturing process [31]

iv. The size of orders of resources and the production run $[31,32]$

v. The nature and type of manufacturing system and manufacturing method employed [33]

\section{Production Planning Network Techniques}

The production network is made up of manufacturing plants that cooperate and share resources. A different element is required to describe the kind of production network, [33]. Thus, many researchers defined different types of networks based on the number of organizations involved. Apart from organizational characteristics, which might have an impact on manufacturing sector network conjunction, the planning principle contributes to the production network to a greater extent as it determines the flow of goods [15]. With several plants in the production network, one of the vital challenges is on delivery coordinate and production plan [21]. Therefore, having examined some of the network techniques in the production planning below, the effective control principle for the network can be a challenge. Therefore, among the basic network analysis methods include [18]. 


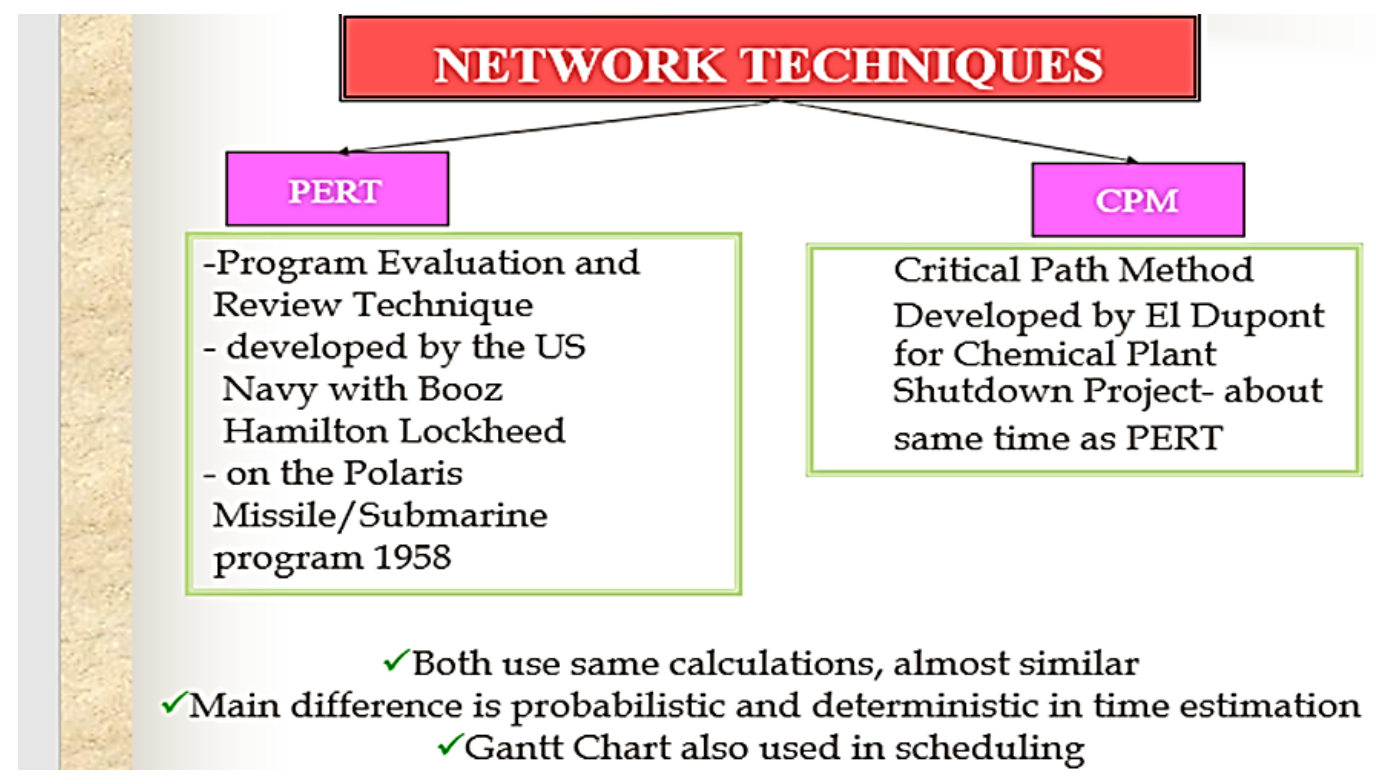

Fig. 1. The difference between CPM and PERT

\subsection{Critical Path Method(CPM)}

The technical procedure of diagramming and network analysis has proven its capacity in managing and controlling the project time and cost [32]. It has helped to clearly indicate the impact of delay on each and each work been done on the entire program, thereby enabling the task of resource management to be much easier [34]. There is a possibility for management, provided one can identify the critical path which is achieved by focusing on the critical activities. Network-based planning of critical path method (CPM) has also shown to be superior in planning methods because it recognizes the path and interrelationship of a giving work in a graphical network, allows one-on-one interaction, give room for responsibilities, and recognize possible option of finishing the project to reduce the incidence of crisis management on projects[35]. Critical path methods (CPM) should be utilized in the planning of a developmental project to surpass the challenges of projects. Critical Path Method (CPM) gives the predominant technique for planning and scheduling. CPM has been a solid foundation in production planning. In CPM tasks can be sorted as deterministic for the estimating of the time taken to finish the network of activities. The assumption of unlimited resources to complete the task and connections are the primary focus in this networking technique. Its limitation is that it does not monitor resources directly [33].

\subsection{Program Evaluation and Review Technique(PERT)}

These techniques function by estimating the probability and uncertainties of the task to be accomplished on a specific date [33]. It has been observed all the task of the network can be integrated and the total duration of the project estimated when simulation methods as
Monte Carlo are in place. Others include GERT Method (Graphical Evaluation and Review Technique) and MPM Method Metra Potential Method [20]. The two (CPM and PERT) have found excellent application in the industries.

\subsection{Critical Chain Method(CCM)}

This technique requires either statistical sophistication or possession of actual distributions of task performance data which does not exist for projects specifically for the construction industry because it has not solved the challenge of time overruns regarding critical Path project planning [34]. One of the most considered ways to account for potential resource constraints on the project is to first recognize the critical path. Moreover [35], CCM estimates task durations by considering an outcome of being completed on time with buffer consideration at the peak of each task to enable risk. These techniques have enhanced project planning by ensuring feasibility and the ability to resist common cause variation through aggregating risk into buffers at the peak of activity paths. CCM planning and project management is easy when compared to different alternative techniques [36]

\subsection{The framework of production planning and control functions in a production network}

Figure 2 indicates that the important task of production planning and control is aimed at synchronization between the partners of a network [38]. Production program planning comprises synchronization between network plants regarding inventory cost. Furthermore, method of planning, capacity and scheduling are vital requirement for manufacturing sector to consider [39]. Thus, the importance of coordination, inventory management, and controlling will become more important for planning in networks than in conventional PPC environments because of the 
multifaceted interrelationships in the processes. The objective is to bring everyone in the production

\begin{tabular}{|l|l|}
\hline $\begin{array}{l}\text { production } \\
\text { program planning }\end{array}$ & $\begin{array}{l}\text { network-adjusted sales planning } \\
\text { network-adjusted requirements and } \\
\text { inventory planning }\end{array}$ \\
\hline $\begin{array}{l}\text { master production scheduling } \\
\text { (conventional) }\end{array}$ \\
\begin{tabular}{|l|} 
basic resource planning allowing for \\
the resources of network partners
\end{tabular} \\
\hline $\begin{array}{l}\text { requirements } \\
\text { planning }\end{array}$ & $\begin{array}{l}\text { mode of procurement: } \\
\text { make, co-operate or buy }\end{array}$ \\
\hline $\begin{array}{l}\text { backward scheduling including for orders } \\
\text { processed in the network }\end{array}$ \\
$\begin{array}{l}\text { capacity requirements planning and } \\
\text { adjustment of plan for possible resource } \\
\text { splitting in the network }\end{array}$ \\
\hline
\end{tabular}

network for the opportunity into a transaction and get adequate information on systems [35].

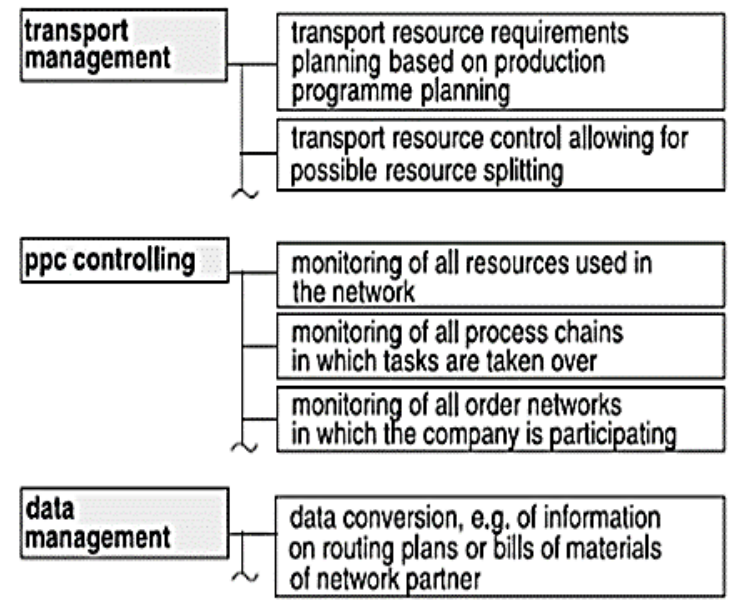

Fig. 2. Production planning and control functions in production network [35]

This paper has established that the Characteristics of the industry involved in production are what determines the type of production Planning and a scheduling method to be applied (Tadei, 1995). Manufacturing is always a concern with component fabrication and assembly, centering attention on queuing work at machines, balancing of output, and making sure every component is made available both for sub and final assembly [40]. In the manufacturing sector, production scheduling is centered majorly on the effective usage of resources and tracking assembly parts [41]. The exact manufacturing process is often influenced to a large extent on a schedule, which therefore direct focus on maintaining continuous production within any constraining situation [42]. Process industries such as food and beverage products are faced with insufficient available time and therefore make use of a production network in tackling the problem. Hence due-date scheduling strategies are applied in production. This challenge is also encountered when there is little or no storage facilities or capacities or where just-in-time production strategies are utilized [42].

\section{Conclusion and recommendation}

It is not quite easy to predict the rate of production exactly and completely in any processing industry. This is because of factors such as non-uniformity of quality of basic resources of raw materials, the difference in process parameters, technological equipment failures, energy supply outages, unforeseen circumstances, among others. It sometimes may not be suitable to apply a scheduling algorithm if the duration of a specific order is hard to define precisely. It is more advisable to combine different strategies such as uniform employment of resources with dynamic bottleneck elimination, priority-based algorithms, and the sequencing of minimal set-up times, among others rather than employing just one method in the production process. As a result of uncertainty process manufacturing, plants'behavior may not be exactly predicted. The planning requires the adoption of diverse online IT applications to respond to the different disturbances and be set up to be able to handle any unexpected events. The use of IT technologies and their products can be harness throughout the manufacturing management system to enhanced production through the application of diverse production model. The available production planning model does not have the capacity to deal with flexible demands of processing industries, most especially medium and small size processing enterprises. This, therefore, required the development of new techniques and methods to settle the issues of demand uncertainty, planning inadequacy, and production capability imbalance. In addition, critical chain method planning is the easiest and convenient when compared to different alternative techniques of a production network.

However, even with the aforementioned limitations, manufacturing systems that are able to filter the best production planning tool or model that suits their operational capabilities and implement or incorporate it into their manufacturing system will be far better than the one that has not incorporated production planning. It is therefore recommended that all manufacturing systems should incorporate a suitable production planning model to enhance the efficiency, effectiveness, and economical value of their system.

The author acknowledged Covenant University for the financial support offered for the publication of this research.

\section{References}

1. Dong, B., Jia, H., Li, Z., \& Dong, K., Systems Engineering Procedia 3, 372 (2012).

2. Bryan, D., 2006. The Weibull analysis handbook. 2nd ed. Milwaukee, WI: ASQ Quality Press. Byrne, M.D. and Hossain, M.M., International Journal of Production Economics, 93, 225 (2005). 
3. Entrup, M.L., Gunther, H.O., van Beek, P., Grunow, M., \& Seiler, T., International Journal of Production Research, Vol. 43, 5071 (2005).

4. Maravelias, C.T., and Sung, Proceeding Foundation of Computer Aided Process Operations (FCAPO). 77, 800 (2008).

5. Afolalu SA, Ikumapayi OM,Abdulkareem A, Soetan SB, Emetere ME, Ongbali SO, Material today: Proceedings., Vol 44, 2895 (2021)

6. Maybodi, M., and Foote, B. Annual of Operations Research, 59, 259 (1995).

7. Mula, J., Poler, R. and Garcia, G.P, Fuzzy Sets and System, vol. 157, 74 (2006).

8. Rekaitis, G.V.. Latin American Applied Research, 30, 285 (2000).

9. Ongbali Samson O, Afolalu Sunday A., Igboanugo Anthony C. International Journal of Mechanical Engineering and Technology, 9, 113 (2018).

10. Kinkel, S., Kirner, E., Armbruster, H., \& Jäger, A. International Journal of Technology Management, 55, 263 (2011).

11. Ikumapayi, O. M., Akinlabi, E. T., Madushele, N., Fatoba, S. O. Advances in Manufacturing Engineering, Lecture Notes in Mechanical Engineering, page 149 (2020).

12. Papageorgiou, L.G., and Pantelides, C.C. Industrial Chemical Engineering Research, 35, 488 (1996).

13. Salawu, E.Y., Okokpujie, I.P., Afolalu, S.A., Ajayi, O.O. and Azeta, J., Journal of Mechanical and Production Engineering Research and Development, 8, 915 (2018).

14. Bitran, G. R., Haas, E. A., \& Hax, A. C. Operations Research, 30, 232 (1982).

15. Feng, P., Zhang, J., Wu, Z., \& Yu, D. International Journal of Production Research, 49, 4223 (2011).

16. Akkerman, R., \& van Donk, D. P. Cognition, Technology and Work, 11, 215 (2009).

17. Jiang, R.Y., Weibull Beijing: Science Press(1998).

18. Kall, P. and Mayer, J., Springer's International Series. New York: Springer. 44, 455 (2005).

19. Elewa, R. E., Afolalu, S. A., \&Fayomi, O. S. I. In Journal of Physics: Conference Series Vol. 1378, 022069 (2019).

20. Lee, J., Journal of Research and Development, 51, 489 (2007).

21. Kopanos, G.M., Lainez, J.M., and Puigjaner, L., Industrial and Engineering Chemistry Research, 48, 6346 (2009).

22. Lodwick, W.A. and Bachman, K.A., Fuzzy Optimization and Decision Making, 4, 257 (2005).

23. Ongbali Samson, O., Afolalu Sunday, A., \& Salawu Enesi, Y, Technology, 10, 606 (2019).

24. Sunday A. Afolalu, Oluwasegun J. Adelakun, Samson O. Ongbali, Abiodun A. Abioye, Oluseyi O.Ajayi, Oloyede Olamilekan R. Proceedings of the World Congress on Engineering-WCE (2019).
25. Mula, J., Poler, R., Garcia-Sabater, J.P. and Lorio, F.C. Intl. Journal of Production Economics, 103, 271 (2006).

26. Singhvi, A., et al., Computers and Chemical Engineering, 28, 993 (2004).

27. Liu, X.B., Bo, H.G., et al., In: Proceedings of the 3rd international conference, FSKD. Berlin: Springer-Verlag, 4223, 929 (2006).

28. Loos, P. and Allweyer, T., Computers in Industry, 36, 199 (1998).

29. Sun, C.Y., Hierarchical optimal production control policy for production systems inProcess industry. Institute of Industrial Process Control, Zhejiang University (2002).

30. Sun HL, Xue YF. The International Journal of Advanced Manufacturing Technology.43, 779 (2009).

31. Ikumapayi, O. M., Akinlabi, E. T., Onu, P. Advances in Manufacturing Engineering, Lecture Notes in Mechanical Engineering, page 161 (2020)

32. Masoumeh, K.Z., Mustapha, N., and Daoud, A.K., International Journal of Production Research, 48, 4701 (2009).

33. Sukoyo, Shinobu, M., and Masaki, M., Journal of the Japan Petroleum Institute, 47, 318 (2004).

34. Austin, J.E., EDI Series in Economic Development (2017)

35. Benjaafar, D.C S. \&ElHafsi, M., Management Science, Vol. 52, 1896 (2006).

36. Ongbali Samson O, Afolalu Sunday A., Udo Mfon. International Journal of Mechanical Engineering and Technology, 9, 2396 (2018).

37. Rajaram, K., \& Karmarkar, U.S., Manufacturing \& Service Operations Management, Vol. 6, 253 (2004).

38. Soman, C. A., van Donk, D.P., \& Gaalman, G.J.C., International Journal of Production Economics 108, 191 (2007).

39. Tadei, R., Trubian, M., Avendano, J.L., Croce, F.D., \& Menga, G., European Journal of Operational Research, 87, 564 (1995).

40. Samson, O. O., Afolalu, S. A., Ojo, S. F., \& Oladipupo, S. In Journal of Physics: Conference Series, Vol. 1378, 032072 (2019).

41. Ikumapayi, O.M.,Oyinbo, S.T., Akinlabi, E.T., Madushele, N, Materials Today: Proceedings 26, $1532(2020)$

42. Ikumapayi, O.M., Akinlabi,E.T.,Mwema, F.M., Ogbonna, O.S, Materials Today: Proceedings 26, 3275 (2020) 